\title{
Association of Community Cancer Centers
}

National Cancer Institute

\section{Source}

National Cancer Institute. Association of Community Cancer Centers. NCI Thesaurus.

Code C39326.

A non- $\mathrm{NCl}$-affiliated cancer accreditated network. ACCC Institution/Group Practice

members include more than 650 medical centers, hospitals, oncology practices, cancer programs, state oncology societies, physician groups, medical and radiation oncologists, and others associated with cancer care across the US. This group of org anizations sees more than 40 percent of all new cancer patients in the United States each year. 